\title{
Contingency approach to strategic management: a test of the mediating effect of leader member exchange on the relationship between psychological empowerment and job satisfaction in $21^{\text {st }}$ century workplace
}

\author{
M.Gökhan Bitmiş ${ }^{\mathrm{a}}$, Azize Ergeneli ${ }^{\mathrm{b}}$ \\ ${ }^{a}$ Başkent University, Baglica, Ankara 06530, Turkey \\ ${ }^{b}$ Hacettepe University, Beytepe, Ankara 06800, Turkey
}

\begin{abstract}
This study examined the mediating impact of leader-member exchange (LMX) on the relationship between dimensions of psychological empowerment and job satisfaction. 490 investment consultants, who work for non-bank financial intermediaries were used to test our hypotheses. We predicted that the role of LMX depends on the dimensions of psychological empowerment under investigation. Our results revealed that LMX fully mediated the relationship between competence dimension of psychological empowerment and job satisfaction, while LMX only partially mediated the relationships between meaning, choice, and impact dimensions of psychological empowerment and job satisfaction. These findings are important since previous research has not tested these variables together. Some suggestions for future research are offered.
\end{abstract}

(C) 2011 Published by Elsevier Ltd. Open access under CC BY-NC-ND license.

Selection and/or peer-review under responsibility of 7 th International Strategic Management Conference

Keywords: leader member exchange theory; strategic management; psychological empowerment; job satisfaction

\section{Introduction}

The ultimate challenge companies confront in today's competitive environment is to make better decisions than their competitors and being managed strategically. Strategic management is a process which helps manager to identify and update the organization's missions and objectives and make the decisions for the appropriate strategies to fit the organization to its environment. Through set of decisions and actions; managers allocate physical, financial, and human resources for dealing with environment and achieving the objectives.

\footnotetext{
* Corresponding author. Tel.:+90 3122341044

E-mail address:mgbitmis@yahoo.com
} 
Therefore, after identifying the current position of the organization, managers evaluate the organization's internal and external environment to formulate and implement strategies that provide a distinctive competence. In this ongoing process among other variables, manager's main focus is on the positive internal variables, strengths, which affect the organizational performance. Relevant resources include some tangible assets such as machinery, raw materials and other assets like technology, financial strength, reputation, and human resources. Among these internal variables, managing human resources is accepted critical to obtain objectives as they need the criteria for being a source of sustainable competitive advantage. Therefore, human resources shape organizations' success while implementing strategies.

Effective human resources management depends on the understanding the way people behave within organizations and identifying the key variables that make them work to attain the organizational objectives. Favorable employee attitudes as one of the key variables are desired by management because they tend to be connected with some of the positive organizational outcomes. Employee satisfaction is a hallmark of well-managed organizations and is associated with employee performance, turnover, and absenteeism.

Research results revealed that organizational costs related to poor employee attitudes may severely reduce the organizational competitiveness in $21^{\text {st }}$ century workplace. Therefore, many studies were conducted to identify the factors contributing to job satisfaction. The primary determinants of employee satisfaction are factors intrinsic to the work that employees confront such as recognition, achievement, responsibility, advancement, personal growth, enhanced competence, and meaning of the job. Behavioral scientists suggest that individuals experience job satisfaction when they learn that they have accomplished something that they believe is personally worthwhile or meaningful. Thus, such satisfaction can be obtained when an employee works on a job that allows him to feel personally responsible, makes a feel that job itself is meaningful and provides feedback. As those factors fit in the dimensions of perception of empowerment, the relationship between psychological empowerment and job satisfaction was examined by many researchers. Nevertheless, finding the key variable that is the reason of this relationship seems to be neglected. Therefore, the aim of this study is to understand the mediating role of leader-member exchange (LMX) on the relationship between dimensions of psychological empowerment and job satisfaction. Further, we try to reveal that whether the role of LMX depends on the dimensions of psychological empowerment under investigation.

The article proceeds in the following order. First, we briefly review the literature regarding job satisfaction, psychological empowerment, and leader member exchange theory. Then, we explain in detail the data collection method, analytical procedures, and hypotheses testing. Finally, the results will be discussed.

\section{Literature Review}

\subsection{Job Satisfaction}

Employee attitudes are important to managers as negative attitudes cause absenteeism, turnovers, work slowdowns, grievances, low performance, poor product or service quality, and sum disciplinary problems that result decrease in organizational competitiveness. Weiss (2002) [1] defined job satisfaction as the emotional reactions concerning the duties of employees. Job satisfaction is employees' affective attitudes that express their feelings of like or dislike towards their works. It is a multi-dimensional job-related attitude in which employees evaluate their works considering different elements like pay, relationship with other individuals, nature of tasks performed and working conditions. Those elements can be grouped as job content (the nature of the job) and job context (the supervisors, co-workers, and organization) [2]. Among those major job related elements, the nature of the job is almost always the one most strongly correlated with high levels of overall job satisfaction [3]. $21^{\text {st }}$ century's knowledge workers mostly prefer complex tasks that are non-routine and challenging that demand high job autonomy, employee participation, and empowerment. Spreitzer, et. al. (1997) [4] reported that one of the earliest 
anticipated outcomes of psychological empowerment is job satisfaction. Also, many research revealed that there is positive relationship between psychological empowerment and job satisfaction [4],[5].

\subsection{Psychological Empowerment}

Empowerment in today's workplace has been a popular issue for managers and academics to implement and study. Harari (1994) [6] defined empowerment as giving freedom. This definition is related with the behavior of a supervisor, which is the one aspect of empowerment [7]. However, the act of empowering subordinates is not enough for effective empowerment. Therefore, employees should also be felt empowered, which is the second aspect of the empowerment called psychological state of a subordinate. Thus, empowerment can be defined as the motivational concept of self-efficacy [8]. Depending on the work of Conger and Kanungo (1988) [8], Thomas and Velthouse (1990) [9] characterized a cognitive model of empowerment as intrinsic task motivation that is psychological empowerment, which consisted of four dimensions such as meaningfulness, impact, competence, and choice. Finally, Spreitzer (1995) [10] developed a four-dimensional scale by using the Thomas and Velthouse (1990) [9] model. She renamed meaningfulness as meaning and replaced choice with selfdetermination.

Meaning refers to harmony between the requirements of a work role and an employee's beliefs and values [10],[11]. Impact is the perception of the degree to which an individual feels that he or she can affect strategic and organizational outcomes at work [10], [4]. Competence is an individual's belief in his or her capability to perform task activities efficiently [12]. Finally; self-determination (choice) means using autonomy while performing work behaviors and processes [13].

Spreitzer, et al. (1997) [4] manifested that meaning dimension of empowerment was the strongest predictor of general job satisfaction and impact was found as unrelated to job satisfaction. Carless (2004) [14] found that meaning and competence dimensions of psychological empowerment were the significant predictors of job satisfaction. Meaning was the strongest predictor of job satisfaction and it is positively related to it. Competence was negatively related to job satisfaction. Also, impact was found to be a significant predictor of present job satisfaction, but not general job satisfaction, and finally, choice was not found statistically significant. Therefore, the literature is not clear while evaluating the relationship between dimensions of psychological empowerment and job satisfaction.

\subsection{Leader-Member Exchange Theory}

Leader member exchange (LMX) theory which is built on the social exchange and role theory [15] is another important factor when analyzing the relationship between job satisfaction and psychological empowerment. LMX theory is based on different types of relationships that are developed between leaders and their subordinates. Therefore, it is a relationship-based approach to leadership and emphasizes dyadic relationship between a leader and member [16]. Moreover, the quality of the relationship between leader and his or her subordinates usually examined with the help of LMX [17],[18] and LMX develops around the four dimensions such as affect, loyalty, contribution, and professional respect [19]. Research has shown that high quality LMX is positively related to job satisfaction [20],[21] and empowerment [22],[23],[24]. However, it also remains unclear in the literature that whether LMX does serve as a mediator for the relationship between dimensions of psychological empowerment and job satisfaction. Therefore, the hypotheses of this research are established as follows:

$\mathrm{H}_{1}$ : The relationship between the meaning dimension of psychological empowerment and job satisfaction is mediated by LMX.

$\mathrm{H}_{2}$ : The relationship between the competence dimension of psychological empowerment and job satisfaction is mediated by LMX.

$\mathrm{H}_{3}$ : The relationship between the choice dimension of psychological empowerment and job satisfaction is mediated by LMX. 
$\mathrm{H}_{4}$ : The relationship between the impact dimension of psychological empowerment and job satisfaction is mediated by LMX.

\section{Method}

\subsection{Sample and Data Collection Procedure}

Survey questionnaires were distributed to 210 investment consultants, who work for non-bank financial intermediaries in Turkey. A total of 170 questionnaires from employees were returned . Then the study is expanded in order to reach a large sample for generalization of results. New questionnaires were sent and we reached 550 questionnaires in total. Some of them were discarded due to the excessive missing data, resulting 490 useable questionnaires. The return rate of the questionnaires was $84 \%$. Average age of the participants was 35.33 and $58 \%$ of the participants were male.

\subsection{Measures}

The constructs in our study are developed by using measurement scales adopted from prior studies. Psychological empowerment and LMX scales are measured using five-point Likert scales with anchors strongly disagree $(=1)$ and strongly agree $(=5)$. Psychological empowerment was measured by a 12 items scale which is developed and validated by Spreitzer (1995) [10]. LMX scale consists of the 12 items and originally derived by Liden and Maslyn (1998) [19]. Job satisfaction was assessed by using Global Job Satisfaction scale, which was originally developed by Quinn and Shepard (1974) [25] and subsequently modified by Pond and Geyer (1991) [26]. Scale's response format was also a 5-point Likert scale. Sample questions include: "In general: how much do you like your job?" (Responses range from 1 $=$ not at all to $5=$ great deal.) and "How does this job compare with your ideal job (job you would most like to have) ?" (Responses range from $1=$ very far from ideal to $5=$ very close to ideal.) The Cronbach's Alpha coefficients were 0.89 for psychological empowerment, 0.93 for LMX, and 0.92 for job satisfaction scales.

\section{Analyses and Results}

In order to measure the relative influence of psychological empowerment dimensions on job satisfaction and to test the mediation affect of LMX, correlation analysis and a series of multiple regression analyses were undertaken.

According to Baron and Kenny (1986) [27], we should estimate three regression models in order to test the mediation. First, the mediator is regressed on the independent variable; second dependent variable is regressed on independent variable; and third, dependent variable is regressed on both the independent variable and the mediator. Separate coefficients for each equation should be tested. In order to identify evidence of mediation; the independent variable should affect the mediator in the first equation; the independent variable should affect the dependent variable in the second equation, and the mediator should affect the dependent variable in the third equation. If the effect of the independent variable on the dependent variable is less in the third equation than in the second one, the mediation is established. This is called partial mediation. Perfect or full mediation holds if the independent variable has no effect when the mediator is introduced into the model [27]. Moreover, the Sobel test was also used to measure the significance of the indirect effect of the independent variable on the dependent variable via the mediator [28].

Therefore, we applied Baron and Kenny's (1986) [27] mediation analysis in order to test the hypothesized mediating perspective (wherein LMX is suggested as a mediator of the relationships between dimensions of psychological empowerment and job satisfaction). The results of three regression equations for each dimension of psychological empowerment are compared to determine proposed 
mediating variable. Further, we conducted four separate analyses of Sobel's test in order to examine whether LMX significantly carried the effects of meaning, competence, self determination (choice), and impact on to job satisfaction.

Table 1 presents means, standard deviations, and Pearson correlations for the measures of dimensions of psychological empowerment, leader-member exchange, and job satisfaction. The correlations reveal that job satisfaction was positively correlated with meaning $(.56, \mathrm{p}<.01)$, competence $(.23, \mathrm{p}<.01)$, choice $(.41, \mathrm{p}<.01)$, and impact $(.39, \mathrm{p}<.01)$. All the correlations are statistically significant. Meaning dimension of psychological empowerment was somewhat more highly correlated with the job satisfaction relative to other dimensions. Also, there was statistically significant and positive correlation between leader-member exchange and job satisfaction $(.62, \mathrm{p}<.01)$.

Table 1 Summary Statistics and Correlations

\begin{tabular}{|c|c|c|c|c|c|c|c|c|c|}
\hline & & $\mathbf{M}$ & SD & 1 & 2 & 3 & 4 & 5 & 6 \\
\hline 1 & Meaning & 4.32 & .71 & --- & & & & & \\
\hline 2 & Competence & 4.49 & .52 & $0.43^{* *}$ & --- & & & & \\
\hline 3 & Choice & 3.73 & .91 & $0.38^{* *}$ & $0.30^{* *}$ & --- & & & \\
\hline 4 & Impact & 3.43 & 1.02 & $0.35^{* *}$ & $0.24^{* *}$ & $0.65^{* *}$ & --- & & \\
\hline 5 & Leader-member exchange & 3.88 & .71 & $0.47^{* *}$ & $0.29^{* *}$ & $0.52^{* *}$ & $0.46^{* *}$ & --- & \\
\hline 6 & Job Satisfaction & 3.60 & .86 & $0.56^{* *}$ & $0.23^{* *}$ & $0.41^{* *}$ & $0.39^{* *}$ & $0.62^{* *}$ & -- \\
\hline
\end{tabular}

Table 2 provides three step regression analyses in order to test whether LMX mediates the relationship between meaning and job satisfaction. Step one of the three step approach for mediation examines the relationship between meaning and LMX. . It can be seen that LMX is significantly and positively related to meaning $(\beta=0.47, t=11.96, p<.001)$. Second step examines the relationship between meaning and job satisfaction. It shows that meaning and job satisfaction is also significantly and positively related $(\beta=$ $0.56, \mathrm{t}=14.90, \mathrm{p}<.001)$. The last step analyzes the relationship between meaning and job satisfaction while controlling the proposed mediator, which is LMX. Based on the multiple regression analysis result, we see that the relationship between meaning and job satisfaction when controlling LMX decreases from $\beta=0.56$ to $\beta=0.33$ (Figure 1 ). However, the relationship is still statistically significant $(p<.001)$. Further, we applied Sobel test to measure the significance of indirect effect of meaning on job satisfaction via LMX. The result supports the significance of indirect effect $(\mathrm{z}=8.61, \mathrm{p}<.001)$. Therefore, the necessary conditions for supporting the partial mediation were adequately met. Finally, we support our first hypothesis.

Table 2 Regression Results to Test the Mediating Role of LMX on the Relationship between Meaning and Job satisfaction

\begin{tabular}{|c|c|c|c|c|c|c|c|c|}
\hline & D.V. & I.V. & B & S.E. & $\beta$ & t & p & $\mathbf{R}^{2}$ \\
\hline \multirow[t]{3}{*}{1} & LMX & Meaning & & & & & & \\
\hline & Constant & & 1.822 & 0.175 & - & 10.420 & 0.000 & \\
\hline & Meaning & & 0.477 & 0.040 & 0.477 & 11.962 & 0.000 & 0.22 \\
\hline \multirow[t]{3}{*}{2} & Job Satisfaction & Meaning & & & & & & \\
\hline & Constant & & 0.664 & 0.20 & - & 3.324 & 0.001 & \\
\hline & Meaning & & 0.679 & 0.046 & 0.56 & 14.901 & 0.000 & 0.31 \\
\hline \multirow[t]{4}{*}{3} & Job Satisfaction & $\begin{array}{l}\text { Meaning, } \\
\text { LMX }\end{array}$ & & & & & & \\
\hline & Constant & & -0.361 & 0.193 & - & -1.873 & 0.062 & \\
\hline & Meaning & & 0.411 & 0.045 & 0.339 & 9.091 & 0.000 & \\
\hline & LMX & & 0.562 & 0.045 & 0.464 & 12.454 & 0.000 & 0.48 \\
\hline
\end{tabular}

D.V. = dependent variable, I.V. = Independent variable , B = unstandardized regression coefficient , S.E. $=$ standard error, $\beta=$

standardized regression coefficient 


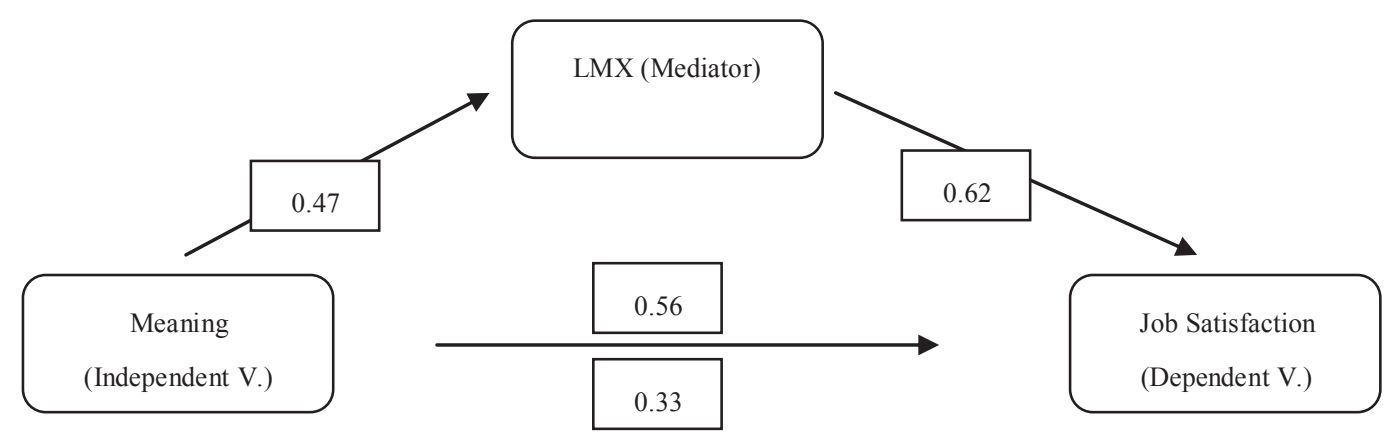

Figure 1: The Mediating Effect of LMX on the Relationship between Meaning and Job Satisfaction

Table 3 also provides three step regression analyses in order to test whether LMX mediates the relationship between competence dimension of psychological empowerment and job satisfaction. Step one of the three step approach for mediation examines the relationship between competence and LMX. . It can be seen that LMX is significantly and positively related to competence $(\beta=0.29, \mathrm{t}=6.88, \mathrm{p}<$ $.001)$. Second step examines the relationship between competence and job satisfaction. It shows that competence and job satisfaction is also significantly and positively related $(\beta=0.23, \mathrm{t}=5.29, \mathrm{p}<.001)$. The last step analyzes the relationship between competence and job satisfaction while controlling the proposed mediator, which is LMX. Based on the multiple regression analysis result, we see that the relationship between competence and job satisfaction when controlling LMX decreases from $\beta=0.23$ to $\beta$ $=0.05$ (Figure 2). However, the coefficient of competence becomes statistically non-significant $(\mathrm{p}=.16)$. Further, we applied Sobel test to measure the significance of indirect effect of competence on job satisfaction via LMX. The result supports the significance of indirect effect $(\mathrm{z}=6.34, \mathrm{p}<.001)$. Therefore, the necessary conditions for supporting the full mediation were adequately met. Finally, we support our second hypothesis.

Table 3 Regression Results to Test the Mediating Role of LMX on the Relationship between Competence and Job satisfaction

\begin{tabular}{|c|c|c|c|c|c|c|c|c|}
\hline & D.V. & I.V. & B & S.E. & $\beta$ & $\mathbf{t}$ & $\mathbf{p}$ & $\mathbf{R}^{2}$ \\
\hline \multirow[t]{3}{*}{1} & LMX & Competence & & & & & & \\
\hline & Constant & & 2.063 & 0.266 & - & 7.741 & 0.000 & \\
\hline & Competence & & 0.406 & 0.059 & 0.298 & 6.888 & 0.000 & 0.08 \\
\hline \multirow[t]{3}{*}{2} & Job Satisfaction & Competence & & & & & & \\
\hline & Constant & & 1.872 & 0.329 & - & 5.681 & 0.000 & \\
\hline & Competence & & 0.385 & 0.073 & 0.233 & 5.292 & 0.000 & 0.05 \\
\hline \multirow[t]{4}{*}{3} & Job Satisfaction & $\begin{array}{c}\text { Competence, } \\
\text { LMX }\end{array}$ & & & & & & \\
\hline & Constant & & 0.349 & 0.280 & & 1.245 & 0.214 & \\
\hline & Competence & & 0.086 & 0.061 & 0.052 & 1.403 & 0.161 & \\
\hline & LMX & & 0.738 & 0.045 & 0.608 & 16.423 & 0.000 & 0.39 \\
\hline
\end{tabular}

D.V. = dependent variable, I.V. = Independent variable , B = unstandardized regression coefficient, S.E. $=$ standard error, $\beta=$ standardized regression coefficient 


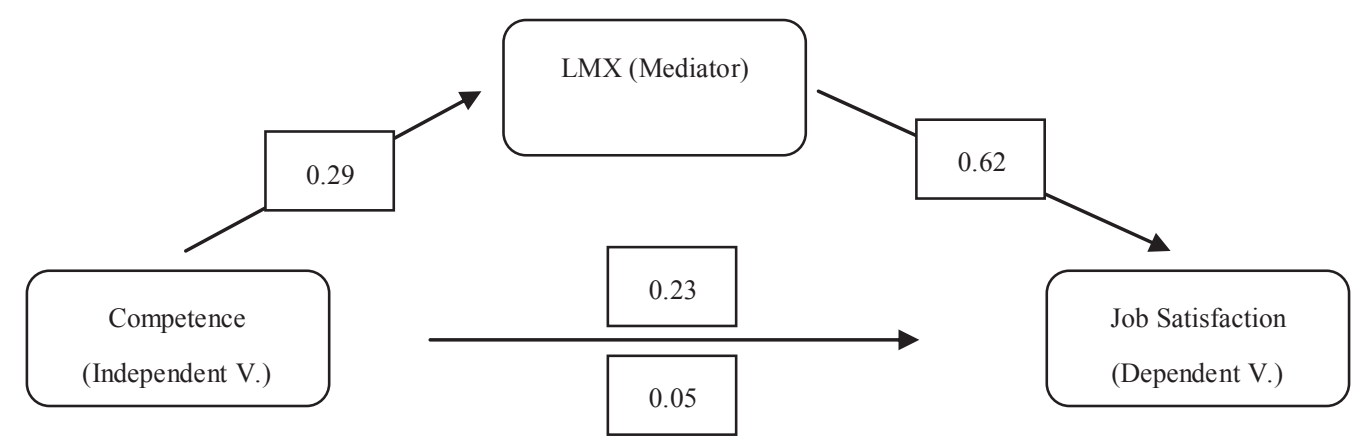

Figure 2: The Mediating Effect of LMX on the Relationship between Competence and Job Satisfaction

Table 4 presents three step regression analyses in order to test whether LMX mediates the relationship between choice and job satisfaction. Step one investigates the relationship between choice and LMX. . It can be seen that LMX is significantly and positively related to choice $(\beta=0.52, t=13.65, p<.001)$. Second step examines the relationship between choice and job satisfaction. It shows that choice and job satisfaction is also significantly and positively related $(\beta=0.41, \mathrm{t}=9.98, \mathrm{p}<.001)$. The last step analyzes the relationship between choice and job satisfaction while controlling LMX. Based on the multiple regression analysis result, we observed that the relationship between choice and job satisfaction when controlling LMX decreases from $\beta=0.41$ to $\beta=0.11$ (Figure 3). Also, the coefficient of choice is still statistically significant $(p<.01)$. Further, we applied Sobel test to measure the significance of indirect effect of choice on job satisfaction via LMX. The result supports the significance of indirect effect $(\mathrm{z}=$ $9.62, \mathrm{p}<.001)$. Therefore, the necessary conditions for supporting the partial mediation were adequately met. Finally, we support our third hypothesis.

Table 4 Regression Results to Test the Mediating Role of LMX on the Relationship between Choice and Job satisfaction

\begin{tabular}{|c|c|c|c|c|c|c|c|c|}
\hline & D.V. & I.V. & B & S.E. & $\beta$ & $\mathbf{t}$ & p & $\mathbf{R}^{2}$ \\
\hline \multirow[t]{3}{*}{1} & LMX & Choice & & & & & & \\
\hline & Constant & & 2.351 & 0.116 & - & 20.323 & 0.000 & \\
\hline & Choice & & 0.411 & 0.030 & 0.526 & 13.654 & 0.000 & 0.27 \\
\hline \multirow[t]{3}{*}{2} & Job Satisfaction & Choice & & & & & & \\
\hline & Constant & & 2.145 & 0.150 & - & 14.258 & 0.000 & \\
\hline & Choice & & 0.391 & 0.039 & 0.412 & 9.982 & 0.000 & 0.17 \\
\hline \multirow[t]{4}{*}{3} & Job Satisfaction & Choice, LMX & & & & & & \\
\hline & Constant & & 0.539 & 0.174 & - & 3.097 & 0.002 & \\
\hline & Choice & & 0.110 & 0.039 & 0.116 & 2.807 & 0.005 & \\
\hline & LMX & & 0.683 & 0.050 & 0.563 & 13.620 & 0.000 & 0.39 \\
\hline
\end{tabular}

D.V. = dependent variable, I.V. = Independent variable , B = unstandardized regression coefficient , S.E. $=$ standard error, $\beta=$ standardized regression coefficient 


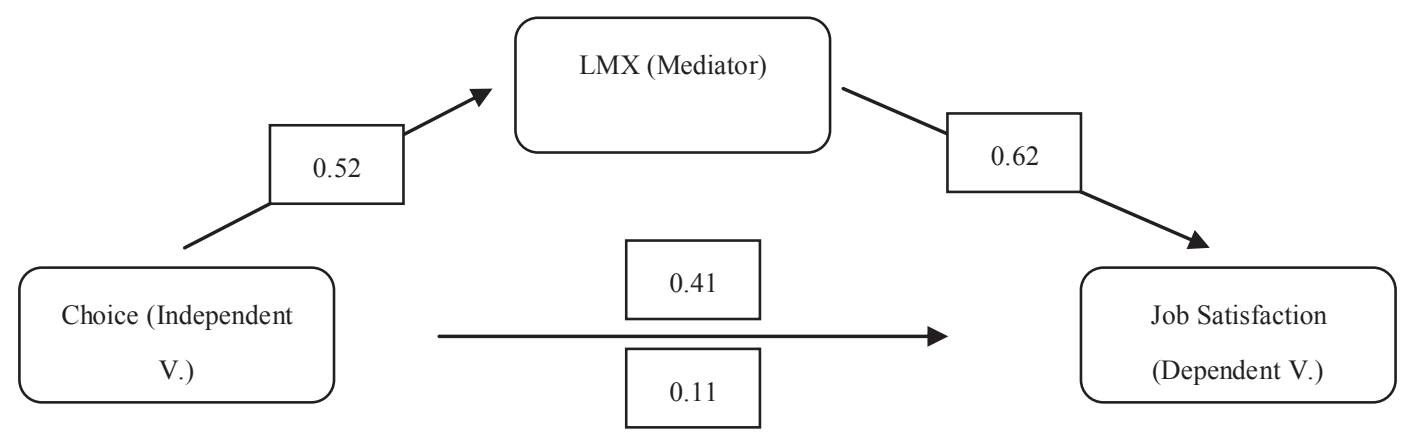

Figure 3: The Mediating Effect of LMX on the Relationship between Choice and Job Satisfaction

Finally, Table 5 presents three step regression analyses in order to test whether LMX mediates the relationship between impact dimension of psychological empowerment and job satisfaction. Step one investigates the relationship between impact and LMX. . It can be seen that LMX is significantly and positively related to impact $(\beta=0.46, \mathrm{t}=11.42, \mathrm{p}<.001)$. Second step examines the relationship between impact and job satisfaction. It shows that impact and job satisfaction is also significantly and positively related $(\beta=0.39, \mathrm{t}=9.36, \mathrm{p}<.001)$. The last step analyzes the relationship between impact and job satisfaction while controlling LMX. Based on the multiple regression analysis result, we observed that the relationship between impact and job satisfaction when controlling LMX decreases from $\beta=0.39$ to $\beta=$ 0.13 (Figure 4). Also, the coefficient of impact is still statistically significant $(p<.01)$. Further, we applied Sobel test to measure the significance of indirect effect of impact on job satisfaction via LMX. The result supports the significance of indirect effect $(\mathrm{z}=8.92, \mathrm{p}<.001)$. Therefore, the necessary conditions for supporting the partial mediation were adequately met. Finally, we support our fourth hypothesis.

Table 5 Regression Results to Test the Mediating Role of LMX on the Relationship between Impact and Job satisfaction

\begin{tabular}{|c|c|c|c|c|c|c|c|c|}
\hline & D.V. & I.V. & B & S.E. & $\beta$ & t & $\mathbf{p}$ & $\mathbf{R}^{2}$ \\
\hline \multirow[t]{3}{*}{1} & LMX & Impact & & & & & & \\
\hline & Constant & & 2.783 & 0.101 & - & 27.651 & 0.000 & \\
\hline & Impact & & 0.320 & 0.028 & 0.460 & 11.422 & 0.000 & 0.21 \\
\hline \multirow[t]{3}{*}{2} & Job Satisfaction & Impact & & & & & & \\
\hline & Constant & & 2.470 & 0.127 & - & 19.525 & 0.000 & \\
\hline & Impact & & 0.330 & 0.035 & 0.391 & 9.367 & 0.000 & 0.15 \\
\hline \multirow[t]{4}{*}{3} & Job Satisfaction & Impact, LMX & & & & & & \\
\hline & Constant & & 0.563 & 0.170 & - & 3.308 & 0.001 & \\
\hline & Impact & & 0.111 & 0.033 & 0.131 & 3.323 & 0.001 & \\
\hline & LMX & & 0.685 & 0.048 & 0.565 & 14.337 & 0.000 & 0.40 \\
\hline
\end{tabular}

D.V. = dependent variable, I.V. = Independent variable , B = unstandardized regression coefficient, S.E.

$=$ standard error, $\beta=$ standardized regression coefficient 


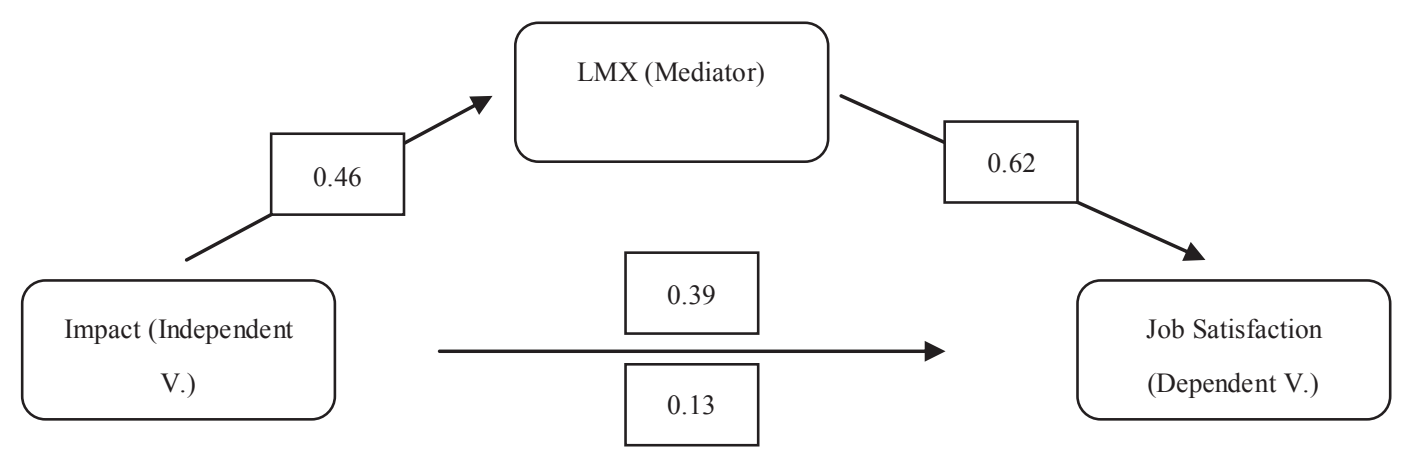

Figure 4: The Mediating Effect of LMX on the Relationship between Impact and Job Satisfaction

All in all, we observed that LMX plays a partial mediator role for the relationship between meaning, choice, and impact dimensions of psychological empowerment and job satisfaction while it plays a full mediator role between competence dimension of psychological empowerment and job satisfaction. Therefore, we support all of our hypotheses.

\section{Discussion}

In order to understand the factors that affect job satisfaction many research have been conducted since it has a very strong effect on organizational outcomes. Among those factors individuals' perception of empowerment has attracted some researchers' attention. According to the study results the higher the psychological empowerment level of the individuals, the greater their job satisfaction. However, the explanatory variables between the psychological empowerment dimensions and job satisfaction were not investigated so far. Therefore, the present study results extend previous research by revealing the role of leader-member exchange quality on the relationship between the dimensions of the psychological empowerment and job satisfaction.

The findings from this study also make a unique contribution to the literature by revealing that LMX plays different roles while examining the psychological empowerment $\rightarrow$ LMX $\rightarrow$ job satisfaction relationship, based on the dimensions of psychological empowerment under investigation. Among four dimensions of psychological empowerment, only the relationship between competence dimension and job satisfaction was fully mediated by the leader-member exchange quality, whereas the relationships between job satisfaction and other dimensions, namely impact, meaning and choice were partially mediated by the leader-member exchange. According to these results, leader-member exchange serves as a critical explanatory variable in the relationship between job satisfaction and competence. In other words, competence does not have a direct effect on job satisfaction when we control LMX. Namely, individuals' competencies were more likely to affect their relation with the leader, which in turn enabled them to have higher job satisfaction. Competent individuals were more likely to strive for accomplishments, which linked to job satisfaction through better relationships with their leaders. Thus, the ones who perceive themselves as having required skills and abilities to do their jobs well, being able to handle the challenges they face, and working efficiently were more likely to work hard and became one of the leaders' in-group employee so that they felt recognized and respected by others, which in turn provide them feeling of job satisfaction.

On the other hand, when individuals feel that they have impact on their job or perceive that their job is meaningful, or they have autonomy at work, those perceptions were directly related to job satisfaction and leader-member exchange partially mediates these relations. These results are incongruence with the result of Dickson \& Lorenz (2009) [29] and Carless (2004) [14] who asserted that job satisfaction was related to meaning and impact dimensions. Thus, leader-member exchange was not the only explanatory variable 
between job satisfaction and the psychological empowerment dimensions of impact, choice and meaning. There are many factors affecting those relations. For example, one can envision that the other variable that might mediate the relationship between the job satisfaction and impact dimension can be stress level of individuals as it is linked to both impact and job satisfaction. It can be assumed that when individuals feel that their decisions affect the result of their job this might increase their feelings of responsibility and their stress level. Some studies reveal that autonomy (choice) support prosocial behavior [30], moral judgments [31] and locus of control that is related to job satisfaction as well. Individuals' perceptions of autonomy can influence job satisfaction via those or some other variables. Those and other variables can be examined for future research. Further, we invite future researchers to analyze our hypotheses in a longitudinal study. This manifests that how LMX relationships and empowerment programs will change over time. Also, the study should be repeated for other samples for generalization of the results.

\section{References}

[1] Weiss, H. M. (2002) 'Deconstructing job satisfaction: Separating evaluations, beliefs and affective experiences', Human Resource Management Review, 12: 173-194.

[2] Newstrom, J.W., and Davis, K. (1997) 'Organizational Behavior: Human Behavior at Work’ McGraw-Hill 10.ed. USA.

[3] Robbins, S.P., Judge, T.A., and Campbell, T.T. (2010) 'Organizational Behavior', Pearson, USA.

[4] Spreitzer, G. M., Kizilos, M. A., and Nason, S. W. (1997) 'A dimensional analysis of the relationship between psychological empowerment and effectiveness, satisfaction, and strain', Journal of Management, 23: 679-704.

[5] Thomas, K., and Tymon, W. (1994) 'Does empowerment always work: Understanding the role of intrinsic motivation and personal interpretation', Journal of Management Systems, 2: 1-13.

[6] Harari, O. (1994) 'Stop Empowering Your People', Small Business Reports, 19(3): 53-5.

[7] Lee, M. and Koh, J. (2001) 'Is empowerment really a new concept?', International Journal of Human Resource Management 12(4): 684-695.

[8] Conger, J. A., and Kanungo, R. N. (1988) 'The empowerment process:Integrating theory and practice', Academy of Management Review, 13: 471-482.

[9] Thomas, K. W., and Velthouse, B. A. (1990) 'Cognitive elements of empowerment: An "interpretive" model of intrinsic task motivation', Academy of Management Review, 15: 666-681.

[10] Spreitzer, G. M. (1995) 'Psychological empowerment in the workplace: Dimensions, measurement, and validation', Academy of Management Journal, 38: 1442-1465.

[11] Hackman, J. R., and Oldham, G. R. (1980) 'Work redesign', Reading, MA: Addison-Wesley.

[12] Gist, M. (1987) 'Self-efficacy: Implications for organizational behavior and human resource management', Academy of Management Review, 12: 472-485.

[13] Bell, N. E., and Staw, B. M. (1989) 'People as sculptors versus sculpture', In M. B. Arthur, D. T. Hall. \& B. S. Lawrence (Eds.\}, Handbook of career theory: 232-251. New York: Cambridge University Press.

[14] Carless, S. A. (2004) 'Does psychological empowerment mediate the relationship between psychological climate and job satisfaction?', Journal of Business and Psychology, 4: 405-425.

[15] Sparrowe, R. and Liden, R. (2005) 'Two Routes To Influence: Integrating Leader-Member Exchange and Social Network Perspectives’, Administrative Science Quarterly, 50: 505-535.

[16] Wilson, K.S., Sin, H.P. and Conlon, D.E. (2010) 'What About The Leader in Leader-Member Exchange? The Impact of Resource Exchanges and Substitutability on the Leader', Academy of Management Review, 35(3): 358-372.

[17] Graen, G. B. (2004) 'New frontiers of leadership, LMX leadership: The series', Greenwich, CT: Information Age Publishing. [18] Graen, G. B., and Uhl-Bien, M. (1995) 'Development of leader-member exchange (LMX) theory of leadership over 25 years: Applying a multi-level multi-domain perspective’, Leadership Quarterly, 6: 219-247.

[19] Liden, R. C., and Maslyn, J. M. (1998) 'Multidimensionality of leader-member exchange: An empirical assessment through scale development', Journal of Management, 24: 43-72.

[20] Epitropaki, O., and Martin, R. (2005) 'From ideal to real: A longitudinal study of the role of implicit leadership theories on leader-member exchanges and employee outcomes’, Journal of Applied Psychology, 90: 659-676. 
[21] Gerstner, C. R., and Day, D. V. (1997) 'Meta-analytic review of leader-member exchange theory: Correlates and construct issues', Journal of Applied Psychology, 82: 827-844.

[22] Liden, R. C., Wayne, S. J., Sparrowe, R. T. (2000) 'An examination of the mediating role of psychological empowerment on the relations between the job, interpersonal relationships and work outcome', Journal of Applied Psychology, 85(3): 407-416.

[23] Ayree, S. and Chen, Z. X. (2006) 'Leader-member exchange in a Chinese context: Antecedents, the mediating mediating role of psychological empowerment and outcomes’, Journal of Business Research, 5: 793-801.

[24] Wat, D., Shaffer, M. A. (2005) 'Equity and relationship quality influences on organizational citizenship behaviors: The mediating role of trust in the supervisor and empowerment', Personnel Review, 34(4): 406-422.

[25] Quinn, R. P., and Shepard, L. J. (1974) ‘The 1972-73 Quality of Employment Survey', Ann Arbor, MI: Institute for Social Research.

[26] Pond, S.B., and Geyer, P.D. (1991) 'Differences in the relation between job satisfaction and perceived work alternatives among older and younger blue-collar workers', Journal of Vocational Behavior, 39: 251-262.

[27] Baron, R. M., \& Kenny, D. A. (1986). 'The moderator-mediator variable distinction in social psychological research: Conceptual, strategic, and statistical considerations', Journal of Personality and Social Psychology, 51, 1173-1182.

[28] Sobel, M. E. (1982). 'Asymptotic intervals for indirect effects in structural equations models'. In S. Leinhart (Ed.), Sociological methodology, San Francisco: Jossey-Bass, 290-312.

[29] Dickson, K.E., \& Lorenz, A., (2009) 'Psychological empowerment and job satisfaction of temporary and part-time nonstandard workers: A preliminary investigation', Journal of Behavioral and Applied Management, 10, 166-192.

[30] Gagné, M. (2003) 'The role of autonomy support and autonomy orientation in prosocial behavior engagement', Motivation and Emotion, 27, 199-223.

[31] Weinstock, M., Assor, A., \& Broide, G. (2009) 'Schools as promoters of moral judgment: the essential role of teachers' encouragement of critical thinking', Social Psychology of Education, 12, 137-151. 